\title{
Synthesis of grafted flocculants based on several kinds of starch and its performance in water turbidity removal
}

\author{
Mujtahid Kaavessina ${ }^{1, *}$, Sperisa Distantina $^{1}$, Fadilah $^{1}$ \\ ${ }^{1}$ Chemical Engineering Department, Sebelas Maret University, 57126 Surakarta, Indonesia
}

\begin{abstract}
Taro starch, cassava starch and also their modified were prepared as a backbone of grafted flocculants. These flocculants were synthesized by combining the properties of synthetic and natural polymer via the 'grafting to' method that separated into two stages. The first stage was synthesizing of nonterminated polyacrylamide (nt-PAM) and then followed by the second stage grafting of the nt-PAM onto several kinds of starch. The intrinsic viscosity $(\eta)$ and average molecular weight (Mv) of starches-g-PAM were observed and their molecular structures were analyzed by using Fourier Transform Infra-Red (FTIR). Finally, the obtained flocculants were tested to evaluate their performance for the treatment of the simulated water turbidity containing $10 \mathrm{~g}$ of kaolin in $1000 \mathrm{ml}$ of aquadest. The results showed that all the grafted flocculants can be good comparable to some commercial organic flocculants. The percentages of the water turbidity removal for each of backbones are 93.6\% (taro starch), 91.2\% (cassava starch), 95.3\% (modified taro starch) and $94.1 \%$ (modified cassava starch). It can be highlighted that the modified taro starch exhibited the best performance in water turbidity removal up to $95 \%$.
\end{abstract}

\section{Introduction}

Wastewater treatment is a multi-stage process to restore water quality from sources of wastewater to be used in a particular need. This process is reducing or removing organic matter, solids, minerals, nutrients, diseasecausing organisms or other contaminants from wastewater. Flocculation is one stage of this treatment. It agglomerates (congregates) the suspended particles into a bigger one (floc) that could be separated by sedimentation and filtration processes [1]. There are two commercial flocculants, i.e.: polymeric flocculants and inorganic coagulating agents. Nayak, et al (2002) affirmed that the polymeric flocculants perform well to form large size of flocs and strongly bound to resist high shear degradation forces in small dosage [2].

Polymer flocculants can be either synthetic or natural. Many researchers reported that synthetic polymers are more effective to bind suspended particles than natural ones. However, their shear stability and biodegradability are poor. In contrast, natural polymers are shear stable, highly biodegradable and non-toxic [3]. Based on this description, the combination properties of synthetic and natural polymer is interested to be developed.

Both blending and copolymerization is combining two or more polymers to obtain new properties that are part of the constituent. Generally, blending is to enhance physical properties of polymers (thermal and mechanical properties). Copolymerization involves chemical reaction by adding a functional group to enhance chemical properties, i,e: hydrophilicity, hydrophobicity, etc. [4].

Polyacrylamide (PAM) is a synthetic polymer which widely used as flocculants. Starch is natural polymer which abundantly available in many sources, i.e.: corn, corn, wheat, corn, potato, taro, cassava, rice, etc. Starch consists of two parts, amylose in a amorphous part (normally $20-30 \%$ ) and amylopectin in a crystalline one (normally $70-80 \%$ ). Both amylose and amylopectin has hydroxyl groups $(-\mathrm{OH})$ that gives an opportunity to be substituted with the other groups. Therefore, polyacrylamide could be attached/grafted onto the starch as the backbone.

Many synthesized flocculants have been reported by grafting PAM onto, amylopectin [5], sodium alginate [6], Glycogen [7], sago starch [8] and corn starch [9]. It can be highlighted that graft copolymers are more effective than the linear ones due to their greater "approachability" to the suspended particles $[2,10]$.

Recently, utilization of many starch sources as backbone was explored, developed and proven their performance as flocculating agent for industrial effluents $[2,10,11]$. Most of them have reported the utilization of native starch. Generally, the physical characteristics of native starch are clarity, odorless, and stickiness. The native starch has some drawbacks in wide range applications such as unstable viscosity to heat, acid and shear forces, weak structure and undesirable gel characteristic. These drawbacks could be tackled by starch modification. Further, this starch was called modified starch.

\footnotetext{
* Corresponding author: $\underline{\text { mkaavessina } @ \text { staff.uns.ac.id }}$
} 
Modified starch is a starch which has been revamped its hydroxyl groups through chemically (esterification, oxidation, etc.) or physically (pre-gelatinization and hydrothermal treatment). As known, the utilization of chemicals in starch modification has good performance (high efficiency), but it has some weakness, i.e.: concerned in points of food safety, and cost of waste water treatment. In other side, physical methods shows no chemical residues that reduces cost in waste water treatment. But it performs in lower efficiency [12].

There are a few reports on the utilization of modified starch as backbone in grafted flocculant. In this investigation, we developed backbone from modified starch and compared their performance to the native one. Modification of starch was done by adding $\alpha$-amylase. The utilization of $\alpha$-amylase is intended to get high efficiency and safety. We report for both native and modified starch of taro and cassava.

\section{Experimental details}

Taro and cassava were supplied from local market in Surakarta, Indonesia. Both were made into taro and cassava starch. The enzyme $\alpha$-amylase, acrylamide, $\mathrm{K}_{2} \mathrm{~S}_{2} \mathrm{O}_{8}$, TMEDA and Hydroquinone were purchased from Sigma Aldrich. Acetone and methanol were kindly supplied by Fulltime. All chemicals were used without any purification.

The preparation of starch-g-PAm was carried out with redox initiation process (synthesizing of nonterminated polyacrylamide (nt-PAM)) and then followed by grafting of the nt-PAM onto several kinds of starch. Polymerization of Acrylamide was initiated by adding $\mathrm{K}_{2} \mathrm{~S}_{2} \mathrm{O}_{8}$ and TMEDA, respectively and was done for 30 $\min$ at $30^{\circ} \mathrm{C}$. This reaction obtained nt-PAM. The optimum initiator concentration $\left(\mathrm{K}_{2} \mathrm{~S}_{2} \mathrm{O}_{8}\right.$ and TMEDA) was obtained by varying its concentration: $0.05,0.1$, $0.15,0.2$, and $0.25 \mathrm{~mol} / \mathrm{L}$. Backbone was prepared by gelatinized of starch at $70^{\circ} \mathrm{C}$ until the color changes under a $\mathrm{N}_{2}$ atmosphere. The gelatinized starch was cooled to ambient temperature.

Grafting Nt-PAm onto gelatinized starch was carried out in a round-bottom flask equipped with a reflux condenser, a nitrogen gas inlet, and placed in a magnetic stirrer for $1.5 \mathrm{~h}$. The process conditions are kept at $50^{\circ} \mathrm{C}$ and stirring speed at $250 \mathrm{rpm}$ under a $\mathrm{N}_{2}$ atmosphere. The product was washed by adding aquadest to make a homogeneous slurry. Finally, aseton and methanol were added sequentially to precipitate starch-g-PAM in form of white granules.

Percentage of polymer (Nt-PAm) incorporated in starch backbone was evaluated by calculating the percentage of grafting yield (\%GY).

$\% G Y=\frac{\mathrm{W}_{3}}{\left(\mathrm{~W}_{1}+\mathrm{W}_{2}\right)} \times 100 \%$

where, $\mathrm{W}_{1}, \mathrm{~W}_{2}$ and $\mathrm{W}_{3}$ are weight of starch, acrylamide, starch graft polyacrylamide, respectively (Qudsieh, 1999).

The molecular structure was determined by A PerkinElmer 630 IR spectrophotometer. It was used to record the IR spectra within the range of $4000-400 \mathrm{~cm}^{-1}$. The IR spectra samples were prepared in solid state using a $\mathrm{KBr}$ pellet method.

Average molecular weight (Mv) of grafted flocculants was determined using the Mark Houwink equation (1):

$\eta=K \cdot M v^{a}$

where, $\mathrm{K}=6,31 \times 10^{-3} \mathrm{~g} / \mathrm{ml}$ dan $\mathrm{a}=0,8$ for PAm in water (Qudsieh,1999).

Flocculation test was done to clarify the synthetic kaolin suspension (10 g of kaolin in $1000 \mathrm{~mL}$ of aquadest). Grafted flocculant (10 mg) was dissolved into $20 \mathrm{ml}$ aquadest. The solution was taken $4 \mathrm{ml}$ as a dosage in flocculation test and poured into $500 \mathrm{ml}$ of kaolin suspension. The mixture was agitated for $2 \mathrm{~min}$ (120 rpm) and $10 \mathrm{~min}(50 \mathrm{rpm})$, sequentially. Then, it was allowed for $1 \mathrm{~h}$ and its turbidity measured.

\section{Results and discussion}

Enzymatic modification of starch is using $\alpha$-Amylase. The visual appearance of modified starch solution in water is clearer and it has lower viscosity than native starch. Meanwhile, as shown in Figure 1 it can be seen that molecular structure of modified taro starch is unchanged compared to the native one. This phenomena is also occurred for cassava starch.
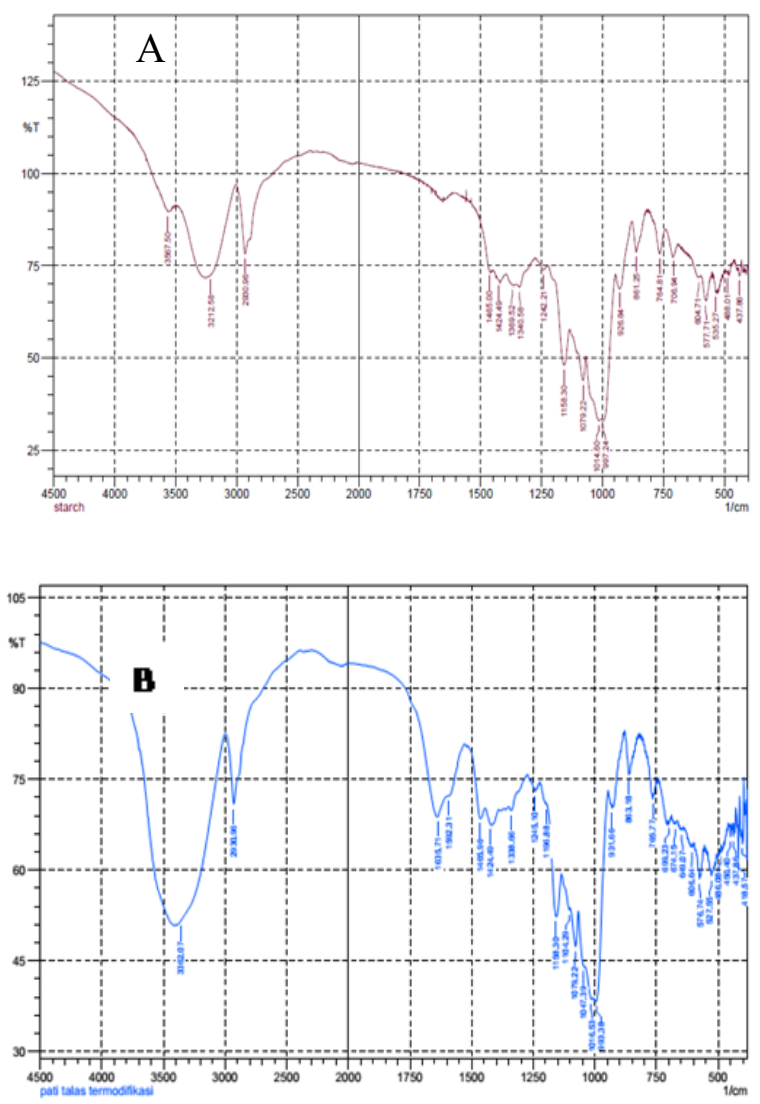

Fig. 1. IR spectrum of native taro starch (A) and modified taro $\operatorname{starch}(\mathrm{B})$. 
The similar IR spectrum of samples was obtained that indicating the same of their molecular structure. The absorption band data of native and modified starch was summarized in Table 1 and 2 . However, it can be highlighted at wave number $3362.07 \mathrm{~cm}^{-1}$. It shows the hydroxyl group $(-\mathrm{OH})$, weak intensity is occurred in native and stronger intensity can be seen in modified one. It indicated that the enzymatic modification can revamp hydroxyl groups in starch. The similar phenomenon is also for cassava starch.

The similar IR spectrum of samples obtained indicating the similarity of their molecular structures. The absorption band data of native and modified starch was summarized in Table 1 and Table 2.

Table 1. Comparison absorption band of native taro starch and modified taro starch

\begin{tabular}{|c|c|c|c|c|}
\hline \multicolumn{2}{|c|}{$\begin{array}{c}\text { Wave number of } \\
\text { taro starch }\end{array}$} & \multirow{2}{*}{$\begin{array}{l}\text { Chemical } \\
\text { Bonding }\end{array}$} & \multirow[t]{2}{*}{ Mode } & \multirow[t]{2}{*}{ Notification } \\
\hline Native & Modified & & & \\
\hline 3362.07 & 3269.92 & $-\mathrm{OH}$ & Stretching & $\begin{array}{l}\text { stronger } \\
\text { intensity after } \\
\text { modification }\end{array}$ \\
\hline 1579.22 & 1583.40 & $-\mathrm{C}-\mathrm{O}$ & Stretching & \\
\hline $\begin{array}{l}1384.49 \\
1395.96 \\
1420.63 \\
1450.18\end{array}$ & $\begin{array}{c}1370.58, \\
1398.55 \\
1415.60 \\
1445.15\end{array}$ & $-\mathrm{CH}-$ & $\begin{array}{c}\text { Deforma- } \\
\text { tion }\end{array}$ & $\begin{array}{l}\text { asymmetric, } \\
\text { symmetric }\end{array}$ \\
\hline 1237.21 & 1256.42 & $-\mathrm{C}-\mathrm{OH}$ & Bending & \\
\hline 871 & 900,8 & $-\mathrm{C}-\mathrm{C}-$ & Stretching & \\
\hline
\end{tabular}

It shows the weak intensity of hydroxyl group $(-\mathrm{OH})$ is occurred in native and stronger intensity can be seen in modified one. It indicated that the enzymatic modification can revamp hydroxyl groups in starch. The similar phenomenon is also for cassava starch.

Table 2. Comparison absorption band of native cassava starch and modified cassava starch

\begin{tabular}{|c|c|c|c|c|}
\hline \multicolumn{2}{|c|}{$\begin{array}{l}\text { Wave number of } \\
\text { cassava starch }\end{array}$} & \multirow{2}{*}{$\begin{array}{r}\text { Chemical } \\
\text { Bonding }\end{array}$} & \multirow[t]{2}{*}{ Mode } & \multirow[t]{2}{*}{ Notification } \\
\hline Native & Modified & & & \\
\hline 3419.94 & 3419.92 & $-\mathrm{OH}$ & Stretching & $\begin{array}{c}\text { stronger } \\
\text { intensity after } \\
\text { modification }\end{array}$ \\
\hline 1643.42 & 1643.40 & $-\mathrm{C}-\mathrm{O}$ & Stretching & \\
\hline $\begin{array}{l}1340.58, \\
1368.55, \\
1420.63, \\
1460.18\end{array}$ & $\begin{array}{l}1340.58, \\
1368.55 \\
1420.60, \\
1460.15\end{array}$ & $-\mathrm{CH}-$ & $\begin{array}{l}\text { Deforma- } \\
\text { tion }\end{array}$ & $\begin{array}{l}\text { asymmetric, } \\
\text { symmetric }\end{array}$ \\
\hline 1242.21 & 1268.21 & $-\mathrm{C}-\mathrm{OH}$ & Bending & \\
\hline 890 & 921.1 & $-\mathrm{C}-\mathrm{C}-$ & Stretching & \\
\hline
\end{tabular}

Figure 2 shows that the greater of the initiator concentration, the percentage of grafting yield $(\% \mathrm{GY})$ tends to increase. It could be explained as follows: the presence of initiator acts as stimulator of the active radical formation (non-terminated polyacrylamide/ntPAM). Increasing initiator concentration provides more opportunity of formation acrylamide chains in active radical form that will be grafted on backbone starch. Thus, $\% \mathrm{GY}$ tends to increase. From this figure, the maximum value of $\% \mathrm{GY}$ is obtained at $91.51 \%$ when the initiator concentration is $0.2 \mathrm{M}$. This value is maximum in the range of initiator concentration between $0.05-0.25$ M.

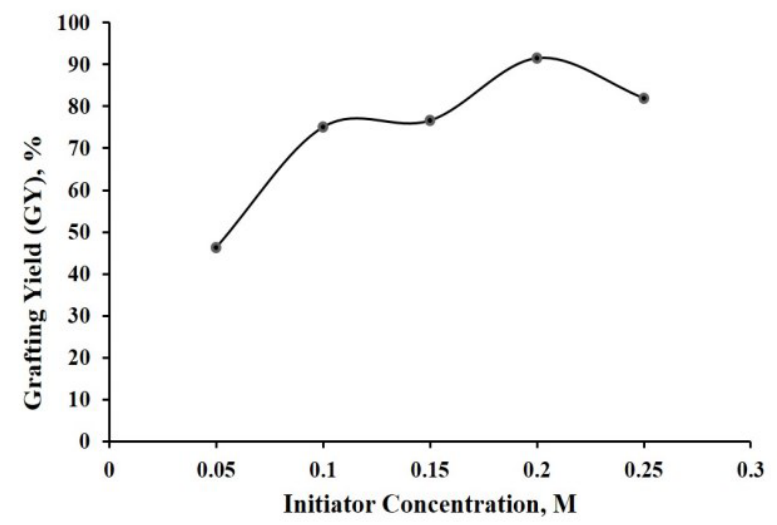

Fig. 2. The effect of initiator concentration towards percentage of grafting yield (\%GY).

Above $0.2 \mathrm{M}$, the percentage of grafting yield begins to decrease. This phenomena may be caused by the formation of polyacrylamide in homopolymer form. The excess initiator during polymerization of poly acrylamide leads to the incorporation of the formed active radicals in polyacrylamide chains that configure terminated polyacrylamide (without active radicals).

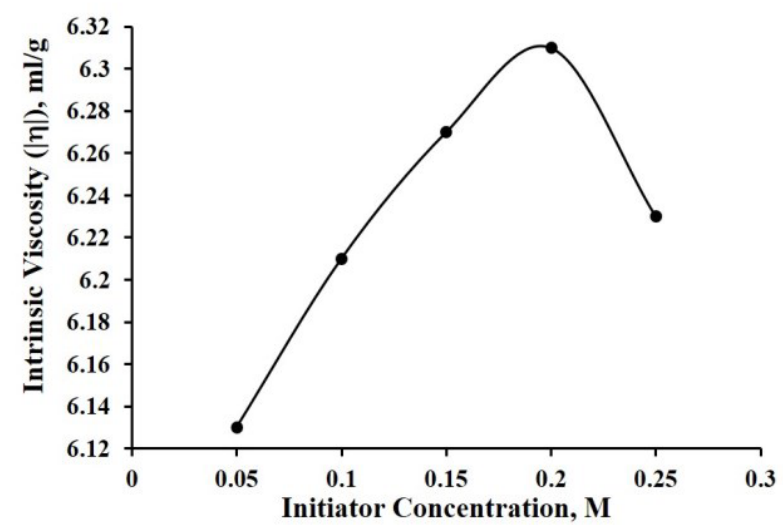

Fig. 3. The effect of initiator concentration towards intrinsic viscosity $(|\eta|)$

The effect of initiator concentration toward intrinsic viscosity was also investigated as depicted in Figure 3. It can be highlighted that similar trend with $\% \mathrm{GY}$ was occurred. The greater of the initiator concentration, the intrinsic viscosity $(|\eta|)$ shows increasing trend. The 
maximum value of intrinsic viscosity is $5,625 \times 10^{3} \mathrm{~g} / \mathrm{mol}$ when the initiator concentration is $0.2 \mathrm{M}$. However, above $0.2 \mathrm{M}$, The depletion of intrinsic viscosity was also occurred. It can be concluded that there is a correlation between the percentage of grafting yield and intrinsic viscosity.

As the correlation with intrinsic viscosity, molecular weight of grafted flocculant has same trend. It can be seen in Figure 4. The maximum molecular weight of grafted flocculant is $5625 \mathrm{Da}$ in the range of initiator concentration between 0.05-0.25 M. The maximum value was obtained at $0.2 \mathrm{M}$. Based on this initial data, the initiator concentration was set at $0.2 \mathrm{M}$ for further investigation

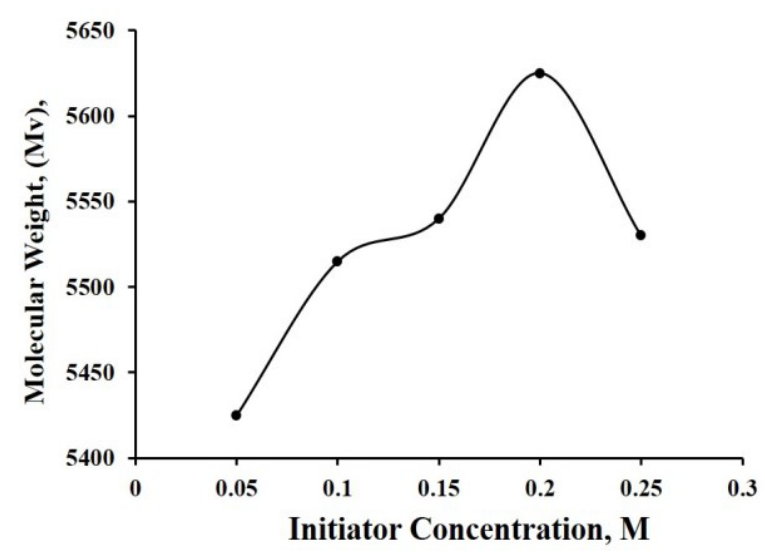

Fig. 4. The effect of initiator concentration towards Molecular weight $(\mathrm{Mv})$

Figure 5 depicts the infrared spectrum of starch-gpolyacrylamide. It can be seen that some peaks of pure starch indicating its chemical bonds: $1158.30 \mathrm{~cm}^{-1}$ for C$\mathrm{O} ; 3438.26 \mathrm{~cm}^{-1}$ for $-\mathrm{OH} ; 1394.59 \mathrm{~cm}^{-1}, 2926.14 \mathrm{~cm}^{-1}$, and $2853.81 \mathrm{~cm}^{-1}$ for $\mathrm{C}-\mathrm{H}$, and $880.34 \mathrm{~cm}^{-1}$ for C-C. Figure 3 also shows other peaks indicating the presence of polyacrylamide i.e.: $1193,99 \mathrm{~cm}^{-1}$ and $1240,28 \mathrm{~cm}^{-1}$ for C-N. The presence of chemical bonds for starch and polyacrylamide in sample is verifying that starch-gpolyacrylamide has successfully synthesized.

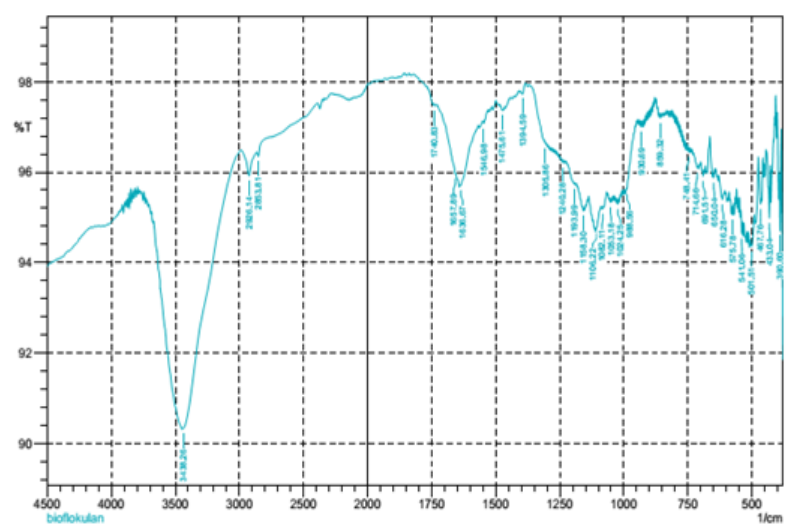

Fig. 5. IR spectrum of starch-g-polyacrylamide (modified taro starch)
Intrinsic viscosity and molecular weight of starch-gPAm (grafted flocculant) were summarized in Table 3. It can be seen that higher molecular weight was obtained from modified taro starch as backbone. Backbone comparison between native and modified starch is monitored and it is shown that the modified one is always higher their molecular weight than the native starch. It may be explained that this phenomenon related to the alteration of hydroxyl groups.

Table 3. Summary of intrinsic viscosity $|\eta|$ and average molecular weight (mv)

\begin{tabular}{|l|c|c|c|c|}
\hline $\begin{array}{c}\text { Graft co- } \\
\text { polymer* }\end{array}$ & $\begin{array}{c}\text { Back- } \\
\text { bone, } \mathbf{g}\end{array}$ & $\begin{array}{c}\text { Acrylamide, } \\
\mathbf{M} \text { (4 ml) }\end{array}$ & $\begin{array}{c}|\eta|, \\
\mathbf{~ m l / g}\end{array}$ & $\mathbf{M v . 1 0}^{\mathbf{3}}$ \\
\hline Sample A & 2.5 & 0.1 & 6.9 & 6.288 \\
\hline Sample B & 2.5 & 0.1 & 6.3 & 5.612 \\
\hline Sample C & 2.5 & 0.1 & 7.4 & 6.862 \\
\hline Sample D & 2.5 & 0.1 & 7.05 & 6.459 \\
\hline
\end{tabular}

Enzymatic modification using $\alpha$ amylase is breaking the cell wall of starch granules followed by the release of amylase or amylopectin. Thus, hydroxyl groups of both amylase and amylopectin are easier to be substituted with non-terminated polyacrylamide. This claim will be studied further for the next investigation.

Further, the graft copolymers were tested to treat the artificial turbid water containing a kaolin suspension. The results were summarized in Table 4 . It shows that higher molecular weight of graft copolymer is more effective to turbidity removal in water. This phenomenon might be related to the quantity of polyacrylamide grafted in the backbone. As explained above, modified starch give the easiness of hydroxyl groups to be substituted with radical group of non-terminated polyacrylamide (nt-PAm). However, it needs further investigation to support this statement.

Table 4. Flocculation performance for each graft copolymers

\begin{tabular}{|l|c|c|c|c|}
\hline \multirow{2}{*}{ Criteria } & \multicolumn{4}{c|}{ Sample * } \\
\cline { 2 - 5 } & A & B & C & D \\
\hline $\mathrm{pH}$ & 6.5 & 6.5 & 6.5 & 6.5 \\
\hline Temperature, ${ }^{\circ} \mathrm{C}$ & 30 & 30 & 30 & 30 \\
\hline Dosage, mg/L & 2.67 & 2.67 & 2.67 & 2.67 \\
\hline $\begin{array}{l}\text { Initial Turbidity, } \\
\text { NTU }\end{array}$ & 180 & 180 & 180 & 180 \\
\hline $\begin{array}{l}\text { Residual Turbidity, } \\
\text { NTU }\end{array}$ & 11.52 & 15.84 & 8.46 & 10.62 \\
\hline Removal, \% & 93.6 & 91.2 & 95.3 & 94.1 \\
\hline
\end{tabular}

Modified taro starch-g-Pam, Sample D= Modified cassava starch-g-Pam 


\section{Conclusions}

Combination of synthetic and natural polymer was successfully prepared through the graft copolymerization. Non-terminated polyacrylamide can be grafted onto a backbone either in the form of native or modified starch. Average molecular weight related to the intrinsic viscosity was observed to increase after modification. The obtained starch-g-polyacrylamide performed the effectively flocculation to kaolin suspension in water. This result showed that the graft copolymer is potential to be applied for water turbidity removal or treatment process of wastewater.

This research was financially supported by Sebelas Maret University through research grant of "Hibah Peneliti Utama sebagai Rujukan Hibah MRG-UNS PNBP 2016”.

\section{References}

[1] R.P. Singh, T. Tripathy, G.P. Karmakar, S.K. Rath, N.C. Karmakar, S.R. Pandey, K. Kannan, S.K. Jain, N.T. Lan, Curr. Sci. 78, 798-803 (2000).

[2] B.R. Nayak, D.R. Biswal, N.C. Karmakar, R.P. Singh, Bull. Mater. Sci. 25, 537-540 (2002).

[3] C.L. Swanson, R.L. Shogren, G.F. Fanta and S.H. Imam, J. Environ. Polym. Degr. 1/2, 155 (1993)

[4] M. Kaavessina, A. Ilias, R.H. Elleithy, S.M. Alzahrani, S.M., J. Polym. Res. 19/2, 1-12 (2012).

[5] S.K Rath, R.P. Singh, J. Polym. Sci. 66, 721-729 (1997).

[6] T. Tripathy, S.R. Pandey, N.C. Karkamar, R.P. Bhagat, R.P. Singh, Eur. Polym. J. 35 2057-2072 (1999).

[7] P. Adhikary, K.N. Tiqari, R.P. Singh, J. Appl. Polym. Sci, 103, 773-778 (2007).

[8] I.Y. Qudsieh, A. Fakhru' 1-Razi, N.A. Kabbashi, M.E.S. Mirghani, K.G. Fandi, M.Z. Alam, S.A. Muyibi, M.M. Nasef, J. Appl. Polym. Sci. 109, 3140-3147 (2008).

[9] M. Gao, Z.Q. Xu, Adv. Mat. Res. 875-877, 44-48 (2014).

[10] C.S. Lee, J. Robinson, M.F. Chong, Process Saf. Environ. 92, 489-508 (2014).

[11] Y.J. Sun, G.F. Guo, Y.L. Yang, Adv. Mat. Res. 815, 432-436 (2013).

[12] R. Wongsagonsup, P. Deeyai, W. Chaiwat, S. Horrungsiwat, K. Leejariensuk, M. Suphantharika, A. Fuongfuchat, S. Dangtip, Carbohydr. Polym, 102,790-798, (2014) 